\title{
Respiratory effects of biomass fuel combustion on rural fish smokers in a Nigerian fishing settlement: a case control study.
}

\author{
Paul Dienye ${ }^{1}$, Alex Akani ${ }^{1}$, Ita Okokon ${ }^{2}$
}

1. Department of Family Medicine, University of Port Harcourt Teaching Hospital, Nigeria.

2. Department of Family Medicine, University of Calabar, Nigeria.

\begin{abstract}
Backgroud: The aim was to study the prevalence of respiratory symptoms and assess the lung function of fish smokers in Nigeria.

Methods: A case control study was done among fish smokers in Nigeria. Women aged 15 years or older $(\mathrm{n}=210)$ involved in fish smoking and equal number of matched controls were interviewed on respiratory symptoms and their peak expiratory flow rate (PEFR) measured. Data was analysed using chi square test, student's t-test and odd ratios.

Results: Both groups were similar in their personal characteristics. The test group had significantly increased occurrence of sneezing $(153 ; 72.86 \%)$, catarrh $(159 ; 75.71 \%)$, cough $(138 ; 65.71 \%)$ and chest pain $(59 ; 28.10 \%)$ compared with the control group, odds ratio (OR) 2.49, 95\% confidence interval CI (1.62-3.82), P < 0.001), OR 3.77,95\% CI (2.44- 5.85), P < 0.001, OR 3.38, 95\% CI (2.22-5.15), P < 0.001, and OR 6.45,95\% CI (3.22-13.15), P < 0.001, respectively. The mean PEFR of $321 \pm 58.93$ $\mathrm{L} / \mathrm{min}$ among the fish smokers was significantly lower than $400 \pm 42.92 \mathrm{~L} / \mathrm{min}$ among the controls $(\mathrm{p}=0.0001)$.

Conclusion: Fish smokers have increased risk of respiratory symptoms and reduced pulmonary function. There is a need for protective equipment and periodic evaluation.

Keywords: Biomass combustion, respiratory effect, fish smokers, Nigeria.

DOI: http://dx.doi.org/10.4314/ahs.v16i2.20

Cite as: Dienye P, Akani A, Okokon I. Respiratory effects of biomass fuel combustion on rural fish smokers in a Nigerian fishing settlement: a case control study. Afri Health Sci 2016;16(2): 516-523. http:/ / dx.doi.org/10.4314/ahs.v16i2.20
\end{abstract}

\section{Introduction}

Biomass fuels are used by about $50 \%$ of the world population as their primary source of domestic energy for cooking, home heating, and light. ${ }^{1}$ Its uses exceed $80 \%$ in China, India, and sub-Saharan Africa as compared to near $0 \%$ in developed countries. ${ }^{1}$ Indoor air pollution has been ranked by the $\mathrm{WHO}$ as the $10^{\text {th }}$ among preventable risk factors contributing to the global burden of disease. ${ }^{2}$ About 1.5 to 2 million deaths per year worldwide have been attributed to indoor air pollution. ${ }^{3,4}$ In India, indoor air pollution accounts for approximately 500,000 premature deaths, representing 6 of the national burden of disease. ${ }^{5}$ In Nigeria, the rural dwellers, constituting about $70 \%$ of the population ${ }^{6}$ rely almost exclusively on biomass fuels as their main source of energy. The most fre-

\section{Corresponding author: \\ Paul Dienye, \\ Department of Family Medicine, \\ University of Port Harcourt \\ Teaching Hospital, Nigeria \\ Email: pdienye@yahoo.com}

quently used biomass fuel is wood both as unprocessed wood and as charcoal. ${ }^{7}$ Combustion of biomass fuels such as wood and charcoal is known to cause household air pollution (HAP) by their emission of some toxic and irritant substances. ${ }^{8}$ These substances include respirable particulate matter $\left(\mathrm{PM}_{10}\right)$, carbon monoxide $(\mathrm{CO})$, nitrogen and sulfur oxides $\left(\mathrm{NO}_{2}, \mathrm{SO}_{2}\right)$, aldehydes (e.g., formaldehyde), polycyclic aromatic hydrocarbons (e.g., benzopyrene), volatile organic compounds, chlorinated dioxins, and free radicals. ${ }^{9}$ Exposures to these substances have multiple deleterious effects on the respiratory system. ${ }^{10}$ Among them are acute respiratory infection, ${ }^{11}$ chronic bronchitis, ${ }^{12}$ bronchial asthma, ${ }^{13}$ chronic obstructive pulmonary disease (COPD), ${ }^{14}$ tuberculosis ${ }^{15}$ and possibly lung cancer. ${ }^{16}$

Various measures are used in assessing lung function. Among them is the peak expiratory flow rate(PEFR) which is preferred by general practitioners because of the advantages it has over others. ${ }^{17,18,19}$ In Nigeria, the peak flow meter is the instrument that is readily available 
to family physicians and other primary care physicians for the assessment of respiratory function especially in the rural communities. In these communities, the dependence on wood and other forms of biomass fuels appears to be on the rise sequel to the scarcity and increased cost of substitutes such as kerosene and liquid petroleum gas.

In Oyorokoto fishing settlement, the women depend completely on heat generated by the burning of firewood to dry their fish. This emits very noxious fumes which may have deleterious effect to the respiratory system. In a previous study by Akani et al on respiratory symptoms in this fishing settlement, a cross sectional design which has some limitations was used. ${ }^{20}$ In an attempt to address some of these limitations, this case control study was designed to determine the prevalence of respiratory symptoms and assess the lung function of fish smokers in this fishing settlement in Andoni local government area of the Rivers State, Nigeria. We hypothesize that there is no difference in respiratory symptoms and lung function between fish smokers and others who are not so exposed to biomass combustion. It is envisaged that the results of this study will open the eyes of family physicians in the communities on the need for appropriate intervention to prevent the deleterious effect of biomass combustion.

\section{Subjects and methodology \\ Setting}

This study was carried out in the Oyorokoto fishing settlement in the Andoni local government area of the Rivers State. This is an island in the Atlantic Ocean occupied predominantly by fishermen and people involved in fish related occupations. Other inhabitants include few traders, artisans, clergymen and civil servants who work in the local government council offices in the community. The fishermen go into the ocean in their dug-out canoes to fish while the women receive their catch, smoke them in huts which are specially built for that purpose and occasionally are inhabited by the fish smokers and their relations.

\section{Study design}

This was a case control study.

\section{Study population}

The sample population consisted only of women. Male involvement in such domestic activities such as fish smoking is prohibited by the patriarchal nature of the so- ciety. Only women aged between 15 years and 64 years, who had resided in Oyorokoto for at least 12 consecutive months prior to the study, and who had given their consent after the implications of the research had been carefully explained to them, were included in the study.

\section{Selection criteria}

\section{Inclusion criteria}

\section{Non fish smokers:}

According to the definition, non- fish smoker is a person who does not smoke fish.

These persons:

i. Were not dwelling in houses where fish smoking was practiced. In other words, they were not passive inhalers of smoke. Passive inhaler refers to exposure to fire wood combustion products from the activities of others.

ii. Were residents of Oyorokoto fishing settlement as confirmed by history and personal documents for at least 12 consecutive months.

\section{Fish smokers:}

They are the persons who are engaged in fish smoking by burning fire wood.

\section{Exclusion criteria}

The following groups of persons were not included in this study:

i. Persons who were moribund or had a full-fledged picture of cor pulmonale on clinical examination.

ii. Persons who were known to be suffering from bronchial asthma

iii. Males were not included in this study since fish smoking was a predominantly female occupation.

iv. Persons who lived in the same houses as the fish smokers or worked in other places where they are exposed to dusts or fumes such as saw mills.

v. Cigarette smokers.

\section{Sample size determination}

A sample size of 362 (181 cases and 181 controls) was calculated using the formula:

$$
n=\left(\frac{r+1}{r}\right) \frac{(\bar{p})(1-\bar{p})\left(Z_{\beta}+\mathrm{Z}_{\alpha / 2}\right)^{2}}{\left(\mathrm{p}_{1}-p_{2}\right)^{2}}
$$

$\mathrm{n}=$ Sample size in the case group, $\mathrm{r}=$ ratio of controls to cases, $\mathrm{p}=\mathrm{A}$ measure of variability, $\mathrm{Z}_{\beta}=$ Represents the desired power (typically .84 for $80 \%$ power). $\mathrm{p}_{1}-\mathrm{p}_{2}=$ the difference in proportions, $Z \alpha /_{2}=$ the desired level of 
statistical significance (typically 1.96). It was increased to 420 to give room for attrition.

\section{Sampling method}

The sampling method was as described in a previous study. ${ }^{20}$ A matched control for age, weight and height of individuals not involved in the fish smoking was also recruited for every fish smoker enlisted in the study. Matching of the controls for the variables was done to eliminate their confounding effect on PEFR.

\section{Procedure}

Data was collected from participants in their homes by two community health extension workers who were specially trained for this research using a three part questionnaire which was pretested on 20 fish smokers and 20 controls. Their names were not required on the questionnaire and each subject was assured that the information given was solely for scientific purposes and would be kept confidential.

The first part of the questionnaire sought information about the participants' personal characteristics such as age, marital status, occupation, tobacco exposure, level of education, past medical history of bronchial asthma and type of dwelling place.

The second part identified participants who gave an affirmative answer to the questions about definite respiratory symptoms such as catarrh (nasal discharge), sneezing, cough, chest pain and breathlessness.

The third part of the questionnaire recorded the height, weight and the peak expiratory flow rate(PEFR). Their heights were measured in centimeters using a Leicester height measuring stadiometer (Seca Ltd; Birmingham, UK) by standard procedure without shoes. ${ }^{21}$ Their weight was measured using the Hansons bathroom scale (Terraillon UK Ltd; Hempstead, Hertfordshire, UK).

Measurement of the peak flow rate (PEFR) of each subject was obtained with the help of a mini-Wright's peak flow meter (Clement Clarke International Limited, Harlow, UK). This is a very simple instrument which helps to assess the airflow through the airways and thus help to determine the degree of obstruction along them. It is a simple, quick, and inexpensive way of measuring airflow obstruction. It usually detects a narrowing of large and medium-size airways. In a previous study, the sensitivity of an abnormal peak expiratory flow rate in detecting all people with chronic obstructive pulmonary disease was $91 \%$, and for people with moderate or severe chronic obstructive pulmonary disease was 100\%. The specificity of an abnormal peak expiratory flow rate was lower at $82 \% .{ }^{19}$ The peak flow rate was measured with the subjects in standing position without a nose clip and holding the peak flow meter horizontally. A tight fitting disposable cardboard mouth-piece was inserted into the inlet nozzle for every subject. They were asked to place the lips tightly around the mouthpiece. After proper rest, they were asked to take a deep breath and exhale as forcefully as possible in a single blow into the instrument. The procedure was repeated thrice with an interval of half a minute between each attempt and the result of each attempt was recorded in liters per minute. The best of the three readings was recorded. The highest of each three technically acceptable measurements was taken as being representative of the subjects' lung function. This was compared between the groups. In each case, the procedure was first explained and demonstrated to the subject.

\section{Data analysis}

Frequency table was constructed to show the similarity in the personal characteristics of the fish smokers and the controls. Chi square was used to test for association between respiratory symptoms and fish smoking. Odd ratio was used to determine the risk of respiratory symptoms in exposed subjects. Student's $t$-test was used to test for association between the means of continuous variables such as age, height, weight and PEFR. These were done using Excel software and SPSS version 16 (SPSS Inc., Chicago, Illinois, USA), with significant level at $\mathrm{P}<0.05$.

\section{Ethical approval}

Ethical approval of this study was obtained from the Ethical Committee of the University of Port Harcourt Teaching Hospital Port Harcourt, Nigeria.

\section{Results}

There were 210 fish smokers and an equal number of controls. The personal characteristics and PEFR of the fish smokers and the controls are shown in table 1. 
Table 1: Mean of personal characteristics and PEFR of the fish smokers and matched controls at Oyorokoto fishing settlement at the time of the study.

\section{Characteristics}

Age (years)

Height $(\mathrm{cm})$

Weight $(\mathrm{kg})$

PEFR (L/min)

\author{
Fish smokers \\ $(\mathbf{N}=\mathbf{2 1 0})$
}

$31.46 \pm 13.03$

$157 \pm 0.05$

$58.64 \pm 9.88$

$321 \pm 58.93$

$\begin{array}{ll}\begin{array}{c}\text { Control group } \\ \text { (N=210) }\end{array} & \text { p-value } \\ 30.36 \pm 12.58 & 0.416 \\ 158 \pm 0.06 & 0.088 \\ 59.65 \pm 10.46 & 0.338 \\ 400 \pm 42.92 & 0.0001\end{array}$

The fish smokers had significantly increased occurrence of catarrh $(159 ; 75.71 \%)$, sneezing $(153 ; 72.86 \%)$, cough (138; 65.71\%) and chest pain $(59 ; 28.10 \%)$ compared with the control group, odds ratio (OR) 3.77, 95\% confidence interval (CI) (2.44- 5.85), $\mathrm{P}<0.001$, OR 2.49, 95\% confidence interval CI (1.62-3.82), $\mathrm{P}<0.001)$, OR $3.38,95 \%$ CI (2.22-5.15), P < 0.001, and OR 6.45,95\% CI (3.22-13.15), $\mathrm{P}<0.001$, respectively.

Table 2: Frequency of respiratory symptoms among the fish smokers and the controls in Oyorokoto fishing settlement at the time of the study.

Both groups were similar in their personal characteristics $(\mathrm{P}>0.05)$. The mean PEFR of $321 \pm 58.93 \mathrm{~L} / \mathrm{min}$ among the fish smokers was significantly lower than $400 \pm 42.92$ $\mathrm{L} / \mathrm{min}$ among the controls $(\mathrm{p}=0.0001)$. The frequency of respiratory symptoms among the study participants are shown in table 2 .

$\begin{array}{llll}\begin{array}{l}\text { Fish smokers (\%) } \\ \mathbf{N = 2 1 0}\end{array} & \begin{array}{l}\text { Control group (\%) } \\ \mathbf{N = 2 1 0}\end{array} & \text { p-value } & \text { OR (95\% CI) } \\ \text { 153(72.86) } & 109(51.90) & <0.001 & 2.49(1.62-3.82) \\ 57(27.14) & 101(48.10) & & \\ & & & \\ 159(75.71) & 95(45.24) & <0.001 & 3.77(2.44-5.85) \\ 51(24.29) & 115(54.76) & & \\ & & & \\ 138(65.71) & 76(36.19) & <0.001 & 3.38(2.22-5.15) \\ 72(34.29) & 134(63.81) & & \end{array}$

$7(3.33)$

203(96.67)

$1(0.48)$

$* 0.068$

$7.21(0.89-157.29)$

209(99.52)

$59(28.10)$

$151(71.90)$
$12(5.71)$

198(94.29)
$<0.001$

$6.45(3.22-18.15)$

No

Note: OR - Odds ratio, 95\% CI- 95\% Confidence Interval, * Fishers exact test 


\section{Discussion}

This case control study was designed to determine the prevalence of respiratory symptoms and assess the lung function of fish smokers in Oyorokoto fishing settlement in Andoni local government area of the Rivers State, Nigeria. There was increased prevalence of respiratory symptoms and reduced lung function among the fish smokers as compared with the control group.

The increased prevalence of respiratory symptoms among the fish smokers compared with the controls is similar to the findings by Peters et al among fish smokers in Cross Rivers State in Nigeria, ${ }^{22}$ Adewole et al in Northern Nigeria, ${ }^{23}$ and the observations in Malaysian, Indonesian and Singaporean populations during episodes of bush burning. ${ }^{24,25}$ The commonest symptoms with about two to fourfold risk of occurrence were sneezing, catarrh and cough. This corroborates with report from Mexico and Northern Nigeria. ${ }^{12,23}$ These symptoms are the direct effects of air pollution resulting from the combustion of biomass fuels which emit toxic and irritant substances. ${ }^{8}$ These substances are known to have multiple deleterious effects on the respiratory system. ${ }^{10}$ Although chest pain was the least prevalent symptom, it has about six fold risk of occurrence among the fish smokers. This has been described as a symptom which may indicate the presence of a serious or even life-threatening pathologic condition necessitating rapid investigation and timely appropriate therapy. ${ }^{26}$ It is important to note that most of these symptoms are nonspecific, gradual in onset and may be reported by individuals with normal PEFR. ${ }^{27}$ These symptoms may masquerade as acute respiratory infections which may require no further investigations. ${ }^{28}$ This may result in delayed diagnosis with disease progression and missed opportunities for preventing further deterioration. ${ }^{29}$ This has brought to the fore the importance of occupational history in all medical consultations, especially in communities like Oyorokoto fishing settlement.

\section{Lung function tests}

Lung function tests, which hitherto have been used as mere tools for physiologic studies have become valuable tools in clinical investigations to assess the effects of disease and exposure to environmental pollutants such as biomass combustion on lung function. ${ }^{30}$ Among these tests is the peak expiratory flow rate (PEFR) which is significantly lower among the fish smokers as compared to the controls in this study. This is similar to findings in studies elsewhere among people exposed to biomass combustion. $^{12,23,31}$

PEFR indicates the extent of narrowing of the airway and the ability to move air in and out of the lungs. The narrower the tubes, the lower will be the PEFR. ${ }^{32}$ Romieu et al. suggested that the airway narrowing may be due to the effect $\mathrm{PM}_{2.5}$ which is present in biomass smoke. ${ }^{33}$ This is believed to induce oxidative injury to the lungs through their ability to form free radicals and cause airway inflammation and narrowing. ${ }^{33}$

It is curious to note that the PEFR among the fish smokers and the controls in this study are within the ranges for the normal adult Nigerian populations $\mathrm{s}^{34,35}$ and higher than that reported in Calabar, Nigeria among healthy women by Nku et al. ${ }^{36}$ This corroborates with the reports by previous researchers stating that PEFR varies from urban to rural areas and from one region to the other. ${ }^{37}$ This study therefore agrees with the suggestion that normal reference values be established for each region. ${ }^{38}$

\section{The strength and limitations of the study}

Age, height and weight are well established factors which affect peak expiratory flow rate. ${ }^{39,40}$ In this study, there was strict and careful selection of the fish smokers and the matched controls from the same environment. This was evident in the comparison of the mean age, height and weight between the fish smokers and the controls in which no statistically significant difference was observed. This study has limitations. Firstly, it has been reported that higher hour-years of exposure is related to higher occurrence of symptoms. ${ }^{41}$ This should warrant the assessment of the possible effects of chronic exposure in a dose-response fashion by the calculation of cumulative exposure index (hour-years). This was not done in this study since the parameters needed for the calculation are based on report by the participants which is dependent on memory and is subject to recall bias. ${ }^{12}$ We recommend that cumulative exposure index should be calculated in a future study in large fish smoking centres with available quantitative exposure data to decipher the effect of chronic exposure. The design of the study also makes it impossible to interpret properly the causal sequences occurring over time. 
Secondly, the prevalence of respiratory obstruction as manifested by abnormal peak flow rate could not be measured since there are no reference values in the vicinity of this study. A study to establish reference values in this environment is therefore recommended. Thirdly, although PEFR was used in this study, a more accurate result could have been obtained if the FEV1 was used as recommended by the British Thoracic Society. ${ }^{42}$

Fourthly, since the study was conducted in rural community, it was not possible to recruit women who were completely not exposed to biomass combustion. A study comparing PEFR among the fish smokers and women strictly using gas stoves to cook is recommended.

\section{Conclusion}

Despite these limitations, this study shows that fish smokers have increased frequencies and risk of respiratory problems and reduced peak expiratory flow rate. Education of the fish smokers on the use of inexpensive personal protective devices should be embarked upon. It will also be necessary to involve the government and other donor agencies to institute measures aimed at the improvement of their working conditions such as the provision of electric fish dryers and banning the smoking of fishes indoors.

\section{Declaration of conflicting interests}

The authors declare no competing interest with respect to the research.

\section{Authors' contributions}

POD conceived the study and was involved in the design of the study. ABA wrote the protocol. POD and ABA collected the data. POD, ABA and IBO managed the literature searches, analyses of the data, wrote the firsts draft of the manuscript and participated in subsequent revisions. All authors read and approved the final manuscript.

\section{References}

1. Desai M, Mehta S, Smith K. Indoor smoke from solid fuels: assessing the environmental burden of disease at national and local levels. Geneva, Switzerland: World Health Organization; 2004.

2. World Health Organization. The World Health Report 2002: reducing risks, promoting healthy life. Geneva, Switzerland: World Health Organization; 2002.
3. Bruce N, Perez-Padilla R, Albalak R. Indoor air pollution in developing countries: a major environmental and public health challenge. Bull World Health Organ2000;78:1078-1092.

4. Ezzati M, Kammen DM. The health impacts of exposure to indoor air pollution from solid fuels in developing countries: knowledge, gaps, and data needs. Environ Health Perspect 2002;110:1057-1068.

5. Smith KR. Inaugural article: national burden of disease in India from indoor air pollution. Proc Natl Acad Sci USA 2000;97:13286-13293.

6. Momodu MO. Information needs and information seeking behaviour of rural dwellers in Nigeria: a case study of Ekpoma in Esan West local government area of Edo State, Nigeria. Library Review 2002; 51(8): 406-410.

7. Torres-Duque C, Maldonado D, Pérez-Padilla R, Ezzati $\mathrm{M}$, Viegi $\mathrm{G}$ and on behalf of the Forum of International Respiratory Societies (FIRS) Task Force on Health Effects of Biomass Exposure. Biomass Fuels and Respiratory Diseases: A Review of the Evidence. Proc Am Thorac Soc 2008; 5(5): 577-590.doi:10.1513/pats.200707-100RP. 8. Kocbach, B. A., Pagels, J., Yttri, K. E., Barregard, L., Sallsten, G., Schwarze, P. E., Boman, C. Health effects of residential wood smoke particles: the importance of combustion conditions and physicochemical particle properties. Part FibreToxicol. 2009;6: 29. http://dx.doi. org/10.1186/1743-8977-6-29

9. Zelikoff JT, Chen LC, Cohen MD, Schlesinger RB. The toxicology of inhaled woodsmoke. J Toxicol Environ Health 2002;5:269-282.

10. Viegi G, Simoni M, Scognamiglio A, Baldacci S, Pistelli F, Carrozzi L, Annesi-Maesano I. Indoor air pollution and airway disease. Int J Tuberc Lung Dis 2004;8:1401-1415. 11. Mishra V. Indoor air pollution from biomass combustion and acute respiratory illness in pre-school age children in Zimbabwe. Int J Epidemiol 2003; 32: 847-53.

12. Regalado J, Pérez-Padilla R, Sansores R, Páramo Ramirez JI, Brauer M, Paré P, Vedal S. The effects of biomass burning on respiratory symptoms and lung functions in rural Mexican women. Am J RespirCrit Care Med 2006; 174: 901-5.

13. Mishra V. effect of indoor air pollution from biomass combustion on prevalence ofasthma in the elderly. Environ Health Perspectives 2003; 111: 71-7

14. Orozco-Levi M, Garcia-Aymerich J, Villar J, RamírezSarmiento A, Antó JM, Gea J. Wood smoke exposure and risk of chronic obstructive pulmonary disease. Eur Respir J 2006; 27: 542-546. 
15. Shetty N, Shemko M, Vaz M, D'Souza G. An epidemiological evaluation of risk factors for tuberculosis in South India: a matched case control study. Int J Tuberc Lung Dis 2006;10:80-86.

16. Zhao Y, Wang S, Aunan K, Seip HM, Hao J. Air pollution and lung cancer risks in China-a meta-analysis. Sci Total Environ 2006; 366: 500-13

17. Nolan D, White P. FEV1 and PEF in COPD management. Thorax. 1999; 54(5):468-9.

18. Hegewald M J, Lefor M J, Jensen R L, Crapo R O, Kritchevsky S B, Haggerty C L, Bauer D C,Satterfield S, Harris T. Peak Expiratory Flow Is Not a Quality Indicator for Spirometry: Peak Expiratory Flow Variability and FEV1 Are Poorly Correlated in an Elderly Population. Chest 2007; 131:1494 - 499

19. Jackson H, Hubbarb R. Detecting chronic obstructive pulmonary disease using peak flow rate: cross sectional survey. BMJ. 2003; 327(7416): 653-654.

20. Akani AB, Dienye PO, Okokon IB. Respiratory symptoms amongst females in a fishing settlement in the Niger Delta, Nigeria. Afr J Prm Health Care Fam Med. 2011;3(1), Art. \#152, 5 pages. DOI: 10.4102/ phcfm.v3i1.152.

21. Sagher FA, Roushadi MA and Hweta AM. Peak expiratory flow rate nomogram in Libyan school children. $J$ Pediatrics 1999; (5): 560 - 564.

22. Peters EJ, Esin RA, Immananagha KK, Siziya S, Osim EE. Lung function status of some Nigerian men and women chronically exposed to fish drying using burning fire wood. Cent Afr J Med. 1999;45:119-124

23. Adewole OO, Desalu OO, Nwogu KC, Adewole TO, Erhabor GE. Respiratory Symptoms and Lung Function Patterns in Workers Exposed to Wood Smoke and Cooking Oil Fumes (Mai Suya) in Nigeria. Ann Med Health Sci Res. 2013; 3(1): 38-42.

24. WHO. Bi-Regional Workshop on Health Impacts of Haze-Related Air Pollution, Kuala Lumpur, Malaysia, 1998. Geneva: WHO; 1998:1-8 ( PubMed Annex H).

25. Brauer M, Hisham-Hashim J. Indonesia fires: Crisis and reaction. Environ Sci Technol. 1998;32:404-407.

26. Brims FJ, Davies HE, Lee YC. Respiratory chest pain: diagnosis and treatment. Med Clin North Am. 2010;94(2):217-32.

27. Mannino D, Gagnon R, Petty T, Lydick E. Obstructive lung disease and low lung function in adults in the United States: data from the National Health and Nutrition Examination Survey, 1988-1994. Arch Intern Med 2000;160:1683-9.
28. Walters JA, Hansen E, Mudge P, Johns DP, Walters $\mathrm{EH}$, Wood-Baker R. Barriers to the use of spirometry in general practice. Aust Fam Physician 2005; 34:201-3.

29. McKenzie DK, Frith PA, Burdon JG, Town GI. The CO PDX plan: Australian and New Zealand guidelines for the management of chronic obstructive pulmonarydisease. Med J Aust 2003;178:S7-39.

30. Erhabor GE, Fatusi A, Obembe OB. Pulmonary functions in arc-welders in Ile-Ife, Nigeria. East Afr Med J 2001; 78: 461-4.

31. Sukhsohale N D, Narlawar U W, Phatak M S. Indoor Air Pollution from Biomass Combustion and its Adverse Health Effects in Central India: An Exposure-Response Study. Indian J Community Med. 2013; 38(3): 162-167.

32. Diner B, Brenner B, Camargo CA Jr. Inaccuracy of "personal best" peak expiratory flow rate reported by inner-city patients with acute asthma. J Asthma 2001; 38: 127-132.

33. Romieu I, Castro-Giner F, Kunzli N, Sunyer J. Air pollution, oxidative stress and dietary supplementation: a review. EurRespir J, 2008; 31(1), 179-197.

34. Nwafor A., A survey of peak expiratory flow rate and anthropometric characteristics of young Nigerians in Port Harcourt, Pecop. J. Trop. Med. Health. 2004; 1(1),2329.

35. Ebomoyi M.I. and Iyawe V.I., Variations of peak expiratory flow rate with anthropometric determinants in a population of healthy adult Nigerians, Nig J. Phy. Sci., 2005; 20(1-2), 85-89.

36. Nku CO, Peters EJ, Eshiet AI, Bisong S A, Osim E E. Prediction formulae for lung function parameters in females of South Eastern Nigeria. Nigerian Journal of Physiological Sciences. 2006; 21 (1-2):43-47.

37. Hussain G., Zafar S., Ch AA, Ch ZA, Ahmad MZ. Comparative study of peak expiratory flow rate in cigarette smokers and non-smokers of Lahore district. $A n$ nals. 2007: 13( 4): 255-259.

38. Manjunath CB, Kotinatot SC, Babu M. Peak Expiratory Flow Rate In Healthy Rural School Going Children (5-16 Years) of Bellur Region For Construction of Nomogram. J ClinDiagn Res. 2013; 7(12): 2844-2846.

39. Bhardwaj P, Poonam K, Jha K, Bano M. Effects of age and body mass index on peak-expiratory flow rate in Indian population. Indian J Physiol Pharmacol. 2014;58(2):1669.

40. Reddy U N, Umran Khan M A, Anjum S, Nasirmohiuddin M, Pratap Rao S, Narsing Rao J, Afreen S. 
Evaluation of mean peak expiratory flow rate (PEFR) of healthy children belonging to urban areas of Hyderabad. Asian Pac. J. Health Sci. 2014; 1(2):113-119.

41. Mamuya SH, Bråtveit M, Mashalla Y, Moen BE. High prevalence of respiratory symptoms among workers in the development section of a manually operated coal mine in a developing country: A cross sectional study. BMC Public Health. 2007;7:17. doi:10.1186/1471-2458-717. 1.

42. British Thoracic Society. Guidelines for the management of chronic obstructive pulmonary disease. Thorax 1997;52(suppl): S1-28. 